\title{
"Você nos livrará da tirania de William Shakespeare?" - Hamlet na HQ Kill Shakespeare
}

Sirlei Santos Dudalski, Departamento de Letras, Universidade Federal de Viçosa, Viçosa, MG; E-mail: <sirleisantosd@yahoo.com.br>.

\section{Resumo}

As peças de William Shakespeare têm sido infinitamente adaptadas para as mais diversas mídias. Sabe-se que a história das adaptações e apropriações colocam em questão a bardolatria, uma vez que proporcionam a desmistificação do conceito de autoria. Inúmeros são os quadrinhos que adaptam, citam ou ao menos fazem alusão ao autor, para mencionarmos somente este tipo de arte sequencial. Kill Shakespeare é uma história em quadrinhos canadense escrita por Anthony Del Col e Conor McCreary e ilustrada por Andy Belanger que vem sendo publicada desde 2010. A HQ dialoga intensamente com várias peças shakespearianas, apresentando uma miscelânea de personagens e citações provindas da obra do bardo. Nela, ninguém menos do que Hamlet, chamado de shadow king, é o escolhido para acabar com a tirania de Shakespeare, porém há personagens que consideram Shakespeare um grande herói, e até mesmo um Deus. No presente trabalho, pretende-se analisar a saga da personagem Hamlet na HQ Kill Shakespeare, inspirada naquela que é a mais famosa e admirada peça do drama inglês, levando em conta a especificidade da mídia em que está inserida e suas relações com o texto-fonte, conhecido detentor de grande autoridade cultural.

Palavras-chave: Teatro, Literatura, Quadrinhos, Intermidialidade, Hamlet.

Eu apenas queria ajudar esta terra verdejante a se tornar dourada. Mas estes são tempos turbulentos e eu tenho inimigos além das minhas fronteiras. $E$ piores... piores são os que estão dentro delas. Eles semeiam discórdia para colher rebelião. Belicistas mais interessados em tomar o poder do que usá-lo de forma justa. Estes... devotos se mobilizam sob a bandeira de um homem. Alguns dizem que ele é um deus, outros dizem que é meramente um mago. Você deve pará-lo, Hamlet. Você deve nos salvar. Você vai nos libertar da tirania de 
William Shakespeare? (Del Col; Mccreery \& Belanger, 2010, edição 1: 25). ${ }^{1}$

Charles Marowitz em seu livro Recycling Shakespeare (1991) se questiona sobre o papel do clássico. Para ele, se a palavra clássico tem na verdade algum sentido, este deveria ser se referir à uma obra que é capaz de significar novamente, sendo até possível que ela signifique alguma outra coisa (1991:7). Com a proliferação de adaptações, paródias, citações e alusões a Shakespeare nas mídias contemporâneas, será que poderíamos cogitar que a obra shakespeariana passou a significar outra coisa? Acho que, pelo menos, poderíamos admitir que ela não expressa mais o mesmo que antes, uma vez que saiu do pedestal da alta cultura em que fora colocada em determinado momento.

Interessa-nos verificar a presença de Shakespeare na cultura popular e de massa. Para isso, iremos partir da HQ canadense Kill Shakespeare, escrita por Anthony Del Col e Conor McCreary e ilustrada por Andy Belanger. A HQ, publicada a partir de 2010, apresenta uma miscelânea de personagens e citações provindas da obra do bardo. ${ }^{2}$

\footnotetext{
1"I wish only to help this green land become gold. But these are turbulent times and I have enemies beyond my borders. And worse... worse are those within. They sow seeds of discord in orders to reap rebellion. Warmongers more interested in seizing power than managing it justly. These... zealots rally around the banner of a man. Some say he is a god, others say he is merely a wizard. You are to stop him, Hamlet. You are meant to save us. Will you free us from the tyranny of William Shakespeare?" (Del Col; Mccreery \& Belanger, 2010, edição 1: 25). A HQ ainda não foi traduzida para a língua portuguesa. A tradução do trecho apresentado é de Leonardo Pereira e as demais traduções aqui presentes são minhas.

2'É interessante notar que há uma tendência entre os escritores contemporâneos em usarem mais uma variedade de textos do que se apegarem a uma única peça (Castaldo, 2007: 409).
} 
Em Kill Shakespeare, ninguém menos do que Hamlet, chamado de shadow king, é o escolhido para acabar com a tirania de Shakespeare, porém há personagens que consideram a personagem Shakespeare um grande herói, e até mesmo um Deus. No presente trabalho, pretende-se analisar a saga da personagem Hamlet na $\mathrm{HQ}$ Kill Shakespeare, inspirada naquela que é a mais famosa e admirada peça do drama inglês, levando em conta a especificidade da mídia em que está inserida e suas relações com o texto-fonte, conhecido detentor de grande autoridade cultural.

Shakespeare é visto como um ícone literário e, para pegarmos emprestada a importante colocação que Ítalo Calvino faz sobre os clássicos, "nunca terminou de dizer tudo que tinha para dizer" (2001:11). Calvino também continua na sua missão em defesa dos clássicos declarando de forma categórica que "ler os clássicos é melhor do que não ler os clássicos" (2001:11), com o que concordo plenamente. Porém, acredito ainda que as outras artes e as outras mídias contemporâneas também enriquecem os clássicos, uma vez que, através delas, podemos resgatá-los. Como bem nos afirma Robert Stam (as cited in Hutcheon, 2011: 58), as adaptações, apropriações, citações e alusões podem ajudar os clássicos a sobreviverem. Talvez isso ainda pareça heresia para alguns, mas muitos jovens irão ler uma ou mais peças de Shakespeare por causa de um quadrinho, um filme, um programa de televisão ou um jogo de vídeo game.

$\mathrm{Na}$ minha tese de doutorado investiguei o ensino de Shakespeare no Brasil e uma das conclusões às quais cheguei foi que a encenação das peças e os filmes contribuem significativamente para $o$ ensino e a aprendizagem de Shakespeare na Universidade. Hoje, não podemos dissociar o ensino de Shakespeare da presença de sua dramaturgia na cultura popular. Estar ciente dessa "invasão" não significa ser 
bardólatra, mas sim praticar e pensar uma pedagogia condizente com os novos tempos (Dudalski, 2007).

Acredita-se que, cada vez mais, serão usados filmes nas disciplinas que ensinam Shakespeare, já que algumas coleções de $\mathrm{HQ}$ são caras e os programas televisivos são difíceis de gravar (Burt, 2007: 7). Quando se fala em Shakespeare e na sétima arte, ainda vale a pena citar o grande clichê dos dias atuais, que diz que, se Shakespeare estivesse vivo, ele seria um grande roteirista de Hollywood.

Segundo Richard Burt, editor da enciclopédia sobre Shakespeare e a cultura popular e de massa, ninguém nunca havia editado uma antologia sobre o assunto em questão até 2002, a não ser sobre os filmes, porque Shakespeare aparece em tantas mídias e com tanta frequência que seria impossível dar conta de todos os exemplos (Burt, 2002: 5).

Devido às conotações negativas do termo cultura de massa, definida por Burt como cultura imposta ao povo, prefiro utilizar o termo cultura popular, que me parece mais abrangente. $\mathrm{E}$, ainda, diante da complexidade dos termos 'cultura' e 'popular', recorreremos às definições de Raymond Williams em seu livro Palavras-chave: um vocabulário de cultura e sociedade. Segundo ele (2007: 117-121),

Cultura é uma das duas ou três palavras mais complicadas da língua inglesa. Isso ocorre em parte por causa de seu intrincado desenvolvimento histórico em diversas línguas européias, mas principalmente porque passou a ser usada para referir-se a conceitos importantes em diversas disciplinas intelectuais distintas e em diversos sistemas de pensamento distintos e incompatíveis. [...] O sentido primordial referia-se, então, à lavoura, isto é, o cuidado com o crescimento natural. [...] Mas também é preciso reconhecer (iii) o substantivo independente e abstrato que descreve as obras e as práticas da atividade intelectual $e$, particularmente, artística. Com freqüência, esse parece ser hoje o sentido mais difundido: cultura é música, literatura, pintura, escultura, teatro e cinema. 
Eu incluiria os quadrinhos também. Ainda segundo Williams, a cultura popular seria a cultura realmente feita pelo povo e para o povo (2007: 319).

De acordo com Robert Shaughnessy (2007: 1), a linha de pesquisa que estuda Shakespeare e a cultura popular também se interessa pelas indústrias do entretenimento, pela reinvenção, adaptação, citação e apropriação das peças, e mitos e histórias que as circulam, através de uma ampla variedade de mídias em subsequentes períodos e culturas.

Há um relacionamento de mão dupla entre cultura popular e Shakespeare, uma vez que a cultura popular emoldurou a arte de Shakespeare, mas a arte de Shakespeare continua a emoldurar a cultura popular (Prescott, 2010: 271). Sabemos que a arte de Shakespeare era diversa socialmente. Em suas peças, há os rústicos, os soldados, os marinheiros, os pescadores, os cidadãos, os serviçais, os bobos, entre outros, em meio à monarquia e aos generais. Não há como negar a presença das vozes populares no drama shakespeariano, que é extremamente polifônico. O dramaturgo era um artista popular de sua época e suas peças agradavam tanto aos nobres como ao povo. Além de dramaturgo e ator, Shakespeare era um homem de negócios: tornou-se acionista do teatro The Globe, construído do outro lado do Tâmisa e inaugurado em 1599.

Paul Prescott conclui que, sem a plateia popular, as peças de Shakespeare talvez nunca teriam sido escritas. E sem a influência da cultura popular, elas poderiam ter resultado em algo empobrecido (2010: 276).

Kill Shakespeare, como uma grande alusão a Shakespeare, além de ser um objeto estético independente, a exemplo de outras adaptações, pode e deve ser confrontada com a obra shakespeariana. Há enormes ganhos reflexivos quando teorizamos a $\mathrm{HQ}$ em questão como sendo uma obra inerentemente dupla ou multilaminada (Hutcheon, 2010: 28). 
Dessa forma, para falarmos da $\mathrm{HQ}$, não poderíamos deixar de falar de Shakespeare ou, indo bem mais além, diríamos que, para falar de Shakespeare, não poderíamos deixar de falar das suas adaptações, paródias, alusões e outras recriações.

É importante enfatizar que o leitor não encontrará dificuldade alguma em entender a $\mathrm{HQ}$ caso não possua um prévio entendimento da obra do dramaturgo inglês. No entanto, é muito gratificante perceber como as personagens shakespearianas são reutilizadas na trama da HQ. Cada alusão desvendada causa-nos infinita satisfação no momento da descoberta. A história, que já é interessante, torna-se mais atraente por causa dos intertextos com a obra shakespeariana.

No site oficial da $\mathrm{HQ}$, temos a seguinte descrição da história: "Hamlet, Julieta, Falstaff, Romeu e Puck procuram por um mago que pode ter a habilidade de ajudá-los na batalha contra as forças do mal lideradas por Ricardo III, Lady Macbeth e lago. O mago recluso seria William Shakespeare". ${ }^{3}$ Mas não para por aí, pois há diversas alusões a outras peças e outras personagens shakespearianas também estão presentes. Scott Thill é muito feliz ao anunciar em sua crítica que Shakespeare é colocado no liquidificador em Kill Shakespeare. O resultado parece ser interessante para muitos, porém não deixa de causar certa polêmica. Por exemplo, para Ben Crystal, ator e autor do celebrado livro Shakespeare on Toast, a HQ tem infinitas qualidades, já para a shakespeariana Kimberly Cox, a $\mathrm{HQ}$ não faz outra coisa a não ser alienar os leitores. ${ }^{4}$

${ }^{3}<$ http://www.killshakespeare.com/press.html>. Tradução minha.

${ }^{4}$ As opiniões de Ben Crystal e Kimberly Cox podem ser verificadas na íntegra no seguinte site: <http://www.bleedingcool.com/2010/04/12/shakespearan-scholar-andfrank-millers-girlfriend-blasts-kill-shakespeare/> 
Deixando de lado a não menos significativa polêmica com a professora shakespeariana, vale mencionar que a $\mathrm{HQ}$ foi muito bem recebida pela crítica. Também foi indicada a importantes prêmios da indústria dos quadrinhos, como o Harvey e o Joe Shuster.

Devido ao seu grande sucesso, a HQ também deu origem a Kill Shakespeare: The Live Stage Reading, que junta imagens projetadas dos quadrinhos com a leitura e interpretação dos diálogos por atores, sendo tudo bem interativo. Adaptada pelos próprios autores dos quadrinhos, a performance foi exibida pela primeira vez em Toronto, em 2011. Temos então o texto teatral adaptado para os quadrinhos que, por sua vez, retornou aos palcos a partir dessa nova linguagem. Algo no mínimo interessante de se observar.

Vale a pena enfatizarmos também que, durante toda a série, o nome Will é utilizado sempre que se faz referência a um poder divino - "graças a Will", "que Will te guie". Sabemos que Will em inglês também se refere a testamento, o que poderia nos levar a inferir a ligação da obra com a questão do legado. Ao buscar por Will, não estariam as personagens do bem buscando pelo legado deixado por Shakespeare? Ou seja, por si mesmas? Ao tentar se livrarem da suposta tirania de Shakespeare, Ricardo III, Lady Macbeth e lago não estariam tentando no mínimo questionar tal legado?

Hamlet, a peça, é o documento literário mais citado (Garber, 2004: 467). Não parece ser aleatoriamente que justo a personagem Hamlet seja a escolhida por Ricardo III para livrar as personagens da $\mathrm{HQ}$ da suposta tirania de Shakespeare. Nada poderia ser mais sugestivo e metaficcional. Os mocinhos shakespearianos veneram Shakespeare, seu criador, enquanto os vilões shakespearianos clamam por sua eliminação.

Como mostra a $\mathrm{HQ}$, um mês após a morte do rei da Dinamarca, Cláudio já está casado com Gertrudes e possui o reino. Hamlet mata Polônio, como na peça, e é banido do seu 
país com Rosencrantz e Guildenstern. Hamlet é tão perturbado como a personagem shakespeariana. Segundo Ricardo III, Hamlet é a realização da profecia e, se ele realmente ajudá-lo a eliminar William Shakespeare, o vilão promete em troca ressuscitar o pai de Hamlet.

Para que as peças pudessem ser interligadas, alguns detalhes nos roteiros originais foram modificados, principalmente no tocante ao destino e morte das personagens. Como citado anteriormente, Hamlet não participa dos eventos posteriores ao seu exílio, Otelo foi impedido tanto de ferir lago quanto de se matar, Julieta é detida e expulsa de Verona antes de se suicidar, Romeu é trazido de volta à vida do envenenamento por um frade e assim por diante. Essas soluções de narrativa são semelhantes ao que o escritor Alan Moore fez em A Liga Extraordinária (2000), obra com a qual Kill Shakespeare é frequentemente relacionada pela crítica. Mas ao contrário da história de Moore, que junta personagens vitorianas oriundas de livros de variados autores - como o Homem-Invisível de H.G. Wells, o Capitão Nemo de Júlio Verne e o doutor Jekyl de Robert Louis Stevenson -em uma realidade histórica que se assemelha à nossa, a série de Del Col e McCreary pretende mostrar a interação dos protagonistas das diferentes peças de Shakespeare caso existissem em um mesmo universo, criado via magia pelo próprio autor (Pereira \& Dudalski).

Seria a cultura popular ou de massa uma ameaça à literatura e aos professores que a ensinam? Acredito que não. Por outro lado, penso que o estudo da presença de Shakespeare na cultura popular e de massa poderia ser considerado um fator a mais para aumentar o posicionamento crítico por parte dos alunos. Alta literatura e cultura popular podem conviver lado a lado, uma vez que sabemos que os limites entre elas são tênues. Shakespeare sempre foi um dramaturgo extremamente popular, passou a ser considerado da elite e hoje está nas diversas mídias. Certa vez, tive a oportunidade de conversar com uma senhora de muito pouca instrução que me demonstrou conhecer muito sobre Romeu e Julieta, mesmo sem nunca ter lido a obra ou visto uma encenação da peça. Provavelmente conhecia a tragédia shakespeariana por causa da televisão.

As HQ clássicas usam o prestígio de Shakespeare para elevar seu status cultural. Todos sempre se beneficiam do nome 
Shakespeare. O Shakespeare, com ou sem aspas, como diz Marjorie Garber (2008: xviii), tem se tornado língua franca das trocas culturais modernas. Nos mais diversos gêneros e mídias, as obras dialogam com as peças shakespearianas, seus personagens e sua linguagem e têm redefinido e reposicionado o autor e o mundo moderno (Garber, 2008: xxii).

\section{Referências}

Bradley, Lynne. (2011). Graphic and novel: an interview with the creators of Kill Shakespeare. Retrieved from <http://www.canadianshakespeares.ca/i_killshakespeare.cfm.>

Burt, Richard (Ed.). (2007). Shakespeares after Shakespeare: an Encyclopedia of the Bard in Mass Media and Popular Culture. 2 vols. Westport, Connecticut and London: Greenwood Press.

Burt, Richard. (Ed.). (2002). Shakespeare after mass media. New York: Palgrave.

Calvino, Italo. (2001). Por que ler os clássicos. Trad. Nilson Moulin. 7 reimpressão. São Paulo: Companhia das Letras.

Castaldo, Annalisa. (2007). Fictions of Shakespeare and Literary Culture. In: Burt, Richard (Ed.). Shakespeares after Shakespeare: an Encyclopedia of the Bard in Mass Media and Popular Culture. 2 vols. Westport, Connecticut and London: Greenwood Press.

Dudalski, Sirlei Santos. (2007). O ensino da dramaturgia shakespeariana no Brasil: realidade e perspectivas. 2007. Tese (Doutorado em Estudos Linguísticos e Literários em Inglês) Faculdade de Filosofia, Letras e Ciências Humanas, Universidade de São Paulo.

Garber, Marjorie. (2004). Shakespeare after all. New York: Anchor Books.

Garber, Marjorie. (2008). Shakespeare and modern culture. New York: Anchor Books.

Hutcheon, Linda. (2011). Uma teoria da adaptação. Tradução de André Cechinel. Florianópolis: UFSC.

Marowitz, Charles. (1991). Recycling Shakespeare. New York: Applause. (The Applause Acting Series). 
Mccreary, Conor; Col Del, Anthony \& Belanger, Andy. (2010). Kill Shakespeare. San Diego: IDW.

Pereira, Leonardo V. M. \& Dudalski, Sirlei S. (in press). Um quebracabeça de peças elisabetanas. In: Closel, Régis A. B.; Marin, Ronaldo (Orgs.).Shakespeare 450 Anos. São Paulo: Cena IV - Instituto Shakespeare Brasil.

Prescott, Paul. (2010). Shakespeare and popular culture. In: Grazia, Margreta de; Wells, Stanley (Eds.). The New Cambridge Companion to Shakespeare. Cambridge: Cambridge University Press.

"Press and Media". Kill Shakespeare Official Website. Retrieved from $<$ http://www.killshakespeare.com/press.html>.

Shakespeare, William. (2005). The complete works. Oxford: Clarendon Press.

Shaughnessy, Robert (Ed.) (2007). The Cambridge companion to Shakespeare and popular culture. Cambridge: Cambridge University Press.

Thill, Scott. "Kill Shakespeare Comic puts the bard in a blender". Retrieved from < http://www.wired.com/2010/04/Kill-Shakespeare/>.

Williams, Raymond. (2007). Palavras-chave: um vocabulário de cultura e sociedade. Tradução de Sandra Guardini Vasconcelos. São Paulo: Boitempo. 